\title{
Time-domain NMR relaxometry as an alternative method for analysis of chitosan-paramagnetic ion interactions in solution
}

\author{
Flávio Vinícius Crizóstomo Kock ${ }^{\mathrm{a}}$, Tatiana Monaretto ${ }^{\mathrm{a}}$, Luiz Alberto Colnago ${ }^{\mathrm{b}, *}$ \\ a Instituto de Química de São Carlos, Universidade de São Paulo, Avenida Trabalhador São Carlense 400, 13566-590 São Carlos, São Paulo, Brazil \\ b Embrapa Instrumentação, Rua XV de Novembro 1452, 13560-970 São Carlos, São Paulo, Brazil
}

\section{A R T I C L E I N F O}

\section{Article history:}

Received 22 November 2016

Received in revised form 4 January 2017

Accepted 18 January 2017

Available online 21 January 2017

\section{Keywords:}

Relaxometry

Chitosan

Complexation

Paramagnetic ions

NMR

\begin{abstract}
A B S T R A C T
Chitosan (CHI)-paramagnetic ion interactions in aqueous solution as affected by $\mathrm{pH}$ were studied using time-domain NMR (TD-NMR) relaxometry. Longitudinal $\left(\mathrm{T}_{1}\right)$ and transverse $\left(\mathrm{T}_{2}\right)$ relaxation times of CHI solutions with $\mathrm{Fe}^{3+}, \mathrm{Cu}^{2+}$, and $\mathrm{Mn}^{2+}$ were measured using a single-shot pulse sequence named $\mathrm{CP}-$ $\mathrm{CWFP}_{\mathrm{x}-\mathrm{x}}$. The results indicate that $\mathrm{CHI}$ interacted with $\mathrm{Fe}^{3+}$ ions or iron oxide nanoparticles, maintaining the metal ion in solution at $\mathrm{pH}$ ranging from 3 to 5 . Above this $\mathrm{pH}, \mathrm{CHI}$ coagulated and removed Fe ions or nanoparticles, resulting in a clear supernatant. $\mathrm{CHI}$ probably interacted with $\mathrm{Cu}$ ions at $\mathrm{pH} 6.2$ through the deprotonated $\mathrm{CHI}-\mathrm{NH}_{2}$ groups maintaining the relaxation effect in alkaline solution, whereas $\mathrm{Mn}^{2+}$ did not interact with $\mathrm{CHI}$ strongly enough to produce a complex of high stability. The proposed method can also be further exploited in the study of interactions paramagnetic ions with others $\mathrm{CHI}$ and $\mathrm{CHI}$ derivatives as well as of other water-soluble polysaccharides.
\end{abstract}

(c) 2017 Elsevier B.V. All rights reserved.

\section{Introduction}

Due to their polyfunctional metal-binding properties, chitosan (CHI) and $\mathrm{CHI}$ derivatives have been widely studied as ligands for the recovery, separation, and concentration of metal ions as well as for the fabrication of materials intended for optical, catalytic, sorption, and biological applications [1,2]. Therefore, knowing the precise mechanisms involved in CHI-metal ion interactions and in the stability of such complexes in solution is of outmost importance to understand these applications [3].

Although CHI-metal ion interactions in solution have been widely studied, the precise mechanisms participating in this process remain still unclear [4,5]. The most accepted mechanisms involve adsorption [6], coagulation/flocculation [7], and chelation $[3,8]$. Experimental and theoretical [9] studies have indicated that one (pedant model) or more (bridge model) amino groups are comprised in the binding process $[3,4]$.

CHI-metal binding properties and stability in solution have been investigated using several analytical methods [10], including UV-vis spectrophotometry [11], atomic absorption spectrometry [12,13], zeta potential [13], potentiometric titration [1] and inductively couple plasma-optical emission spectroscopy [14].

\footnotetext{
* Corresponding author.

E-mail address: luiz.colnago@embrapa.br (L.A. Colnago).
}

To the best of our knowledge, no studies involving CHI-metal ions have been performed using low-field, time-domain nuclear magnetic resonance (TD-NMR) relaxometry. We have recently demonstrated that TD-NMR relaxometry can be a simple, rapid method to measure $\mathrm{CHI}$ coagulation [15] and solubility product constant [16] as well as to monitor the complexation of paramagnetic ions in solution [17], even in cases where the equipment has instrumental limitation, as long dead time [18]. All these relaxometric studies have been performed as functions of solution $\mathrm{pH}$.

In this paper, we report the use of TD-NMR relaxometry as an alternative method to study $\mathrm{CHI}$-paramagnetic ion interactions and their stability in solution as functions of $\mathrm{pH}$. The method proposed here has measured the influence of water longitudinal $\left(\mathrm{T}_{1}\right)$ and transverse $\left(\mathrm{T}_{2}\right)$ relaxation times, depend upon $\mathrm{CHI}$-paramagnetic ion interactions. These two relaxation times have been measured simultaneously using a new continuous wave free precession pulse sequence, named $\mathrm{CP}_{-} \mathrm{CWFP}_{\mathrm{x}-\mathrm{x}}[19]$.

\section{Experimental}

\subsection{Reagents and sample preparation}

$\mathrm{CHI}$ was purchased from SIGMA-ALDRICH. The average viscosimetric molecular weight (MW) was determined dissolving the polymer in $0.3 \mathrm{~mol} \mathrm{~L}^{-1}$ acetic acid/ $0.2 \mathrm{~mol} \mathrm{~L}^{-1}$ sodium acetate buffer ( $\mathrm{pH} 4.5$ ). The AVS-360 viscometer and the AVS-20 automatic 
burette, both from Schott-Geräte, were used for the viscosity measurements. A glass capillary $(\phi=0.53 \mathrm{~mm})$ containing $15 \mathrm{~mL}$ of the polymer solution was immersed in a water bath maintained at 25 ${ }^{\circ} \mathrm{C} \pm 0.01{ }^{\circ} \mathrm{C}$ and previously programmed volumes of the solvent, were sequentially added to provide the desired dilution. The intrinsic viscosity $(\eta)$ was determined from the extrapolation of the plot $\eta_{\text {sp }} / C$ versus $C$ to infinite dilution, where $\eta_{\text {sp }}$ is the specific viscosity and $\mathrm{C}$ is the concentration for the polysaccharide solution. The estimated value $\left(1.75 \times 10^{5} \mathrm{~g} \mathrm{~mol}^{-1}\right)$ for the molecular weight (MW) was determined from the corresponding intrinsic viscosities ( $\left.\eta]=716 \mathrm{~mL} \mathrm{~g}^{-1}\right)$ and using the Mark-Houwink-Sakurada parameters ( $K=0.074$ and $\alpha=0.76$ ) in agreement to polymer nature, solvent and temperature, in consonance with $[20,21]$.

The degree of deacetylation (DD) was estimated from ${ }^{1} \mathrm{H}$ NMR measurements [21,22]. For these experiments, an appropriate weight of $\mathrm{CHI}$ was dissolved in $1 \%(\mathrm{v} / \mathrm{v}) \mathrm{HCl} / \mathrm{D}_{2} \mathrm{O}$ solution, performing a concentration of $10 \mathrm{mg} / \mathrm{mL}$ upon constant magnetic stirring at room temperature for $24 \mathrm{~h}$ to result in a clear solution. The DD (75.50\%) was determined from the corresponding ${ }^{1} \mathrm{H}$ NMR spectra, considering the intensity of the signals due to methyl hydrogens from acetamido groups $(\approx 2.0 \mathrm{ppm})$ and due to $\mathrm{H}_{2}-\mathrm{H}_{6}(4.1-3.4 \mathrm{ppm})$ [22]. The ${ }^{1} \mathrm{H}$ NMR spectra were acquired at $80^{\circ} \mathrm{C}$ using a Bruker AVANCE II spectrometer $(600.00 \mathrm{MHz}$ for ${ }^{1} \mathrm{H}$ ), without spinning and employing 3-(Trimethylsilyl) propionic2,2,3,3-d4 acid sodium salt (TMSP) as external reference.

For the experiments about the interaction between $\mathrm{CHI}$ and paramagnetic ions, $\mathrm{CHI}$ solution $\left(1.5 \mathrm{~g} \mathrm{~L}^{-1}\right)$ was prepared dissolving undergoing stirring for $48 \mathrm{~h}$, an appropriate amount of this polysaccharide in acetic acid $0.60 \mathrm{~mol} \mathrm{~L}^{-1}(\mathrm{pH} 2.42)$ at room temperature. For the CHI-paramagnetic ion solutions, we employed $\mathrm{CuSO}_{4} \cdot 5 \mathrm{H}_{2} \mathrm{O}$ (SIGMA-ALDRICH, 98\%), $\mathrm{MnSO}_{4} \cdot 5 \mathrm{H}_{2} \mathrm{O}$ (Synth, 98\%), and $\mathrm{FeCl}_{3} \cdot 6 \mathrm{H}_{2} \mathrm{O}$ (Mallinckrodt Chemical, 97\%). The concentrations of these solutions were $0.82 \mathrm{~g} / \mathrm{L}, 0.79 \mathrm{~g} / \mathrm{L}$ and $0.89 \mathrm{~g} / \mathrm{L}$, respectively. To carry out the measurements in the absence of precipitate, samples were centrifuged at $10,000 \mathrm{rpm}$ for $3 \mathrm{~min}$.

\subsection{Methods}

\subsection{1. $\mathrm{pH}$ measurements}

Sample $\mathrm{pH}$ was measured in a $\mathrm{pH}$ meter, model PG1800 (GEHAKA), that was calibrated prior to each run using buffer solutions. For this, Falcon tubes were filled with $5.00 \mathrm{~mL}$ of sample. Once $\mathrm{pH}$ had been adjusted for the desired value with $1.0 \mathrm{~mol} \mathrm{~L}^{-1}$ $\mathrm{NaOH}$ and $\mathrm{HCl}$ solutions, the tube volume was completed to $10.00 \mathrm{~mL}$, to reach ion-CHI final concentrations of $3.30 \times 10^{-3}$ and $6.60 \times 10^{-3} \mathrm{~mol} \mathrm{~L}^{-1}$. Then, $\mathrm{pH}$ was checked again.

\subsubsection{TD-NMR measurements}

The $T_{1}$ and $T_{2}$ relaxation times were measured in a benchtop time-domain NMR spectrometer, Minispec, model BRUKER mq-20 (Germany) equipped with a $0.47-\mathrm{T}\left(20.00 \mathrm{MHz}\right.$ for $\left.{ }^{1} \mathrm{H}\right)$ permanent magnet as well as a $32.00-\mathrm{mm}$-diameter probe. The minispec software was used for data acquisition. All samples were placed into a temperature-controlled spectrometer at $28.0 \pm 0.1^{\circ} \mathrm{C}$.

For the TD-NMR measurements, a rapid pulse sequence named Carr-Purcell continuous wave free precession with phase alternance $\left(C P-C W F P_{x-x}\right)$ was employed. This sequence is able to simultaneously determine both the longitudinal $\left(T_{1}\right)$ and transverse $\left(T_{2}\right)$ relaxation times [19].

The values were obtained by applying a sequence with the following parameters: a train of $2.34-\mu$ s-long $90^{\circ}$ pulses, a time interval between pulses $\left(t_{p}\right)$ of $300 \mu \mathrm{s}$, a recycle delay of $5 \mathrm{~s}, 4$ scans, and 45,000 echoes. In each measurement, $500 \mu \mathrm{L}$ of each solution was used. $T_{1}$ and $T_{2}$ were obtained by the intensity of the NMR signal after the first pulse $\left(\mathrm{M}_{0}\right)$ and in the steady state $\left(\mathrm{M}_{\mathrm{ss}}\right)$, whereas the time constant $\mathrm{T}^{*}$ was obtained by the monoex-
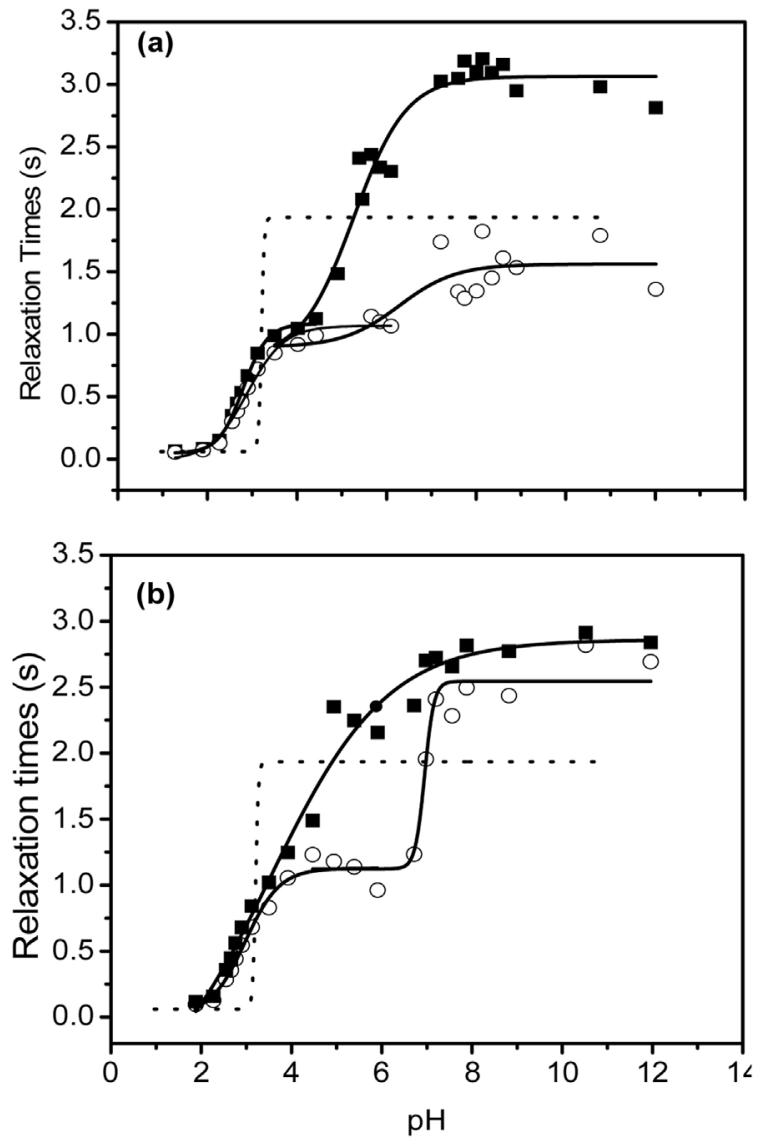

Fig. 1. $T_{1}(\boldsymbol{\square})$ and $T_{2}(\bigcirc)$ relaxometric profiles of chitosan (CHI)-ion samples and supernatant, obtained with $\mathrm{CP}-\mathrm{CWFP}_{\mathrm{x}-\mathrm{x}}$ pulse sequence. a) $\mathrm{CHI}-\mathrm{Fe}^{3+}$ and its respective supernatant. b) Solid and dotted lines are the sigmoidal fitting of experimental data acquired from $\mathrm{CHI}-\mathrm{Fe}^{3+}$ and $\mathrm{Fe}^{3+}$ aqueous solutions, respectively.

ponential fitting of signal decay [18]. Fittings were performed in the Origin ${ }^{\circledR}$ software, version 9.0. All data obtained as affected by $\mathrm{pH}$ were fitted by a Boltzmann sigmoidal curve and corresponded to the average of three measurements. The uncertainty of relaxometric measurements was estimated at $\pm 10 \mathrm{~ms}$ considering the standard deviations of triplicate runs.

\section{Results and discussion}

The interactions between $\mathrm{CHI}$ and the paramagnetic ions $\mathrm{Fe}^{3+}$, $\mathrm{Cu}^{2+}$, and $\mathrm{Mn}^{2+}$ were studied as functions of $\mathrm{pH}$ using TD-NMR relaxometry. These paramagnetic ions were chosen because they precipitate as hydroxides in aqueous solutions at $\mathrm{pH}$ values 3.2 , 7.0, and 9.3, respectively [16]. Therefore, their interactions with $\mathrm{CHI}$ may be studied in a broad $\mathrm{pH}$ range. The $\mathrm{CHI}$ concentration $\left(1.5 \mathrm{~g} \mathrm{~L}^{-1}\right)$ was selected because it is within the ideal range for TD-NMR relaxometry runs [15].

Figs. 1a, 2a, and 3a show the $\mathrm{T}_{1}(\mathbf{\square})$ and $\mathrm{T}_{2}(\mathrm{O})$ relaxometric profiles of samples comprising $\mathrm{CHI}$ and $\mathrm{Fe}^{3+}, \mathrm{Cu}^{2+}$, and $\mathrm{Mn}^{2+}$ as functions of $\mathrm{pH}$. Figs. $1 \mathrm{~b}, 2 \mathrm{~b}$, and $3 \mathrm{~b}$ present the $\mathrm{T}_{1}$ and $\mathrm{T}_{2}$ relaxometric profiles for the same samples, but after being centrifuged. The analyzed portion was the supernatant. Solid lines indicate the sigmoidal fitting of the experimental data for the $\mathrm{CHI}$-ion samples. Dotted lines correspond to the fitting of the respective hydroxide in agreement with Cobra et al. [16]. The experimental data for each ion were not plotted in order to simplify the figure.

These images show the strong effect of $\mathrm{pH}$ in the relaxation profiles of aqueous solution comprising $\mathrm{CHI}$ and paramagnetic ions. Such relaxation profiles were remarkably different from those 

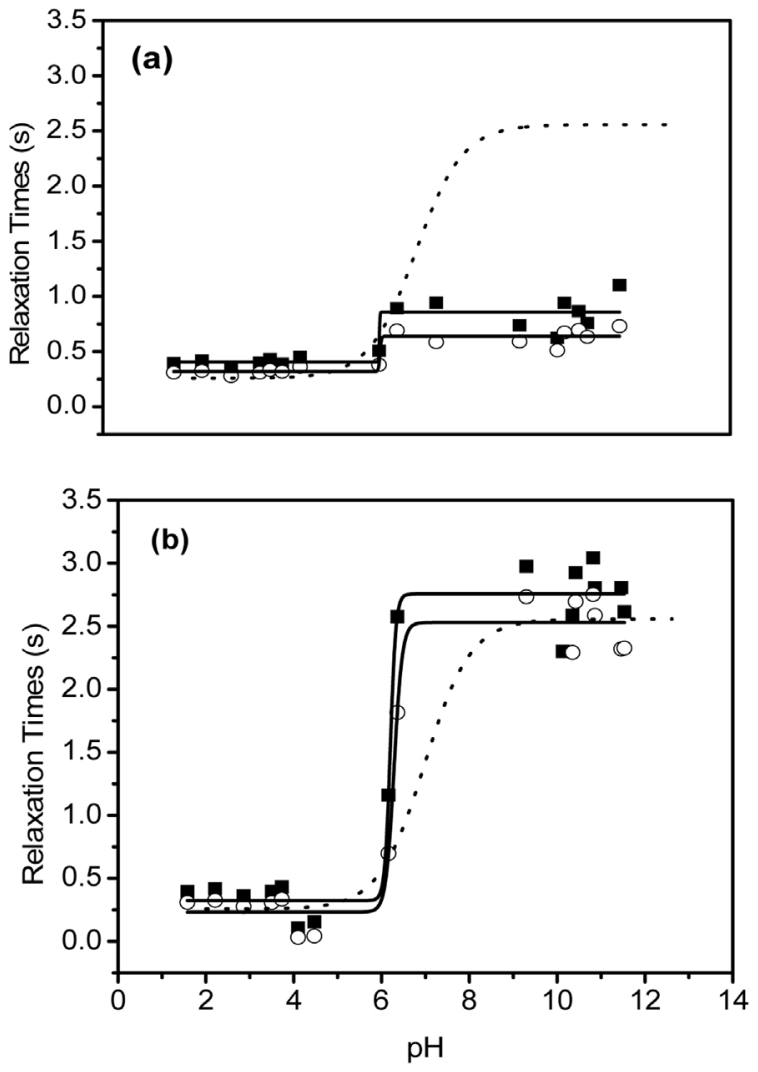

Fig. 2. $T_{1}(\mathbf{\square})$ and $T_{2}(\bigcirc)$ relaxometric profiles of chitosan (CHI)-ion samples and supernatant, obtained with $\mathrm{CP}-\mathrm{CWFP}_{\mathrm{x}-\mathrm{x}}$ pulse sequence. a) $\mathrm{CHI}-\mathrm{Cu}^{2+}$ and its respective supernatant. b) Solid and dotted lines are the sigmoidal fitting of experimental data acquired from $\mathrm{CHI}-\mathrm{Cu}^{2+}$ and $\mathrm{Cu}^{2+}$ aqueous solutions, respectively.

observed for the same $\mathrm{CHI}$ type and concentration in aqueous solution, but in the absence of paramagnetic ions [15]. $\mathrm{T}_{1}$ and $\mathrm{T}_{2}$ values of $\mathrm{CHI}$ aqueous solution showed two plateaus, from $\mathrm{pH} 1$ to 7 and $\mathrm{pH}$ 7 to 10 , with the transitions at approximately $\mathrm{pH} 7$ being related to coagulation [15]. $\mathrm{T}_{1}$ values in the two plateaus were 2.80 and $3.15 \mathrm{~s}$, respectively. $\mathrm{T}_{2}$ values in the two plateaus, from $\mathrm{pH} 1$ to 6 and $\mathrm{pH}$ above 8 , were equal to 2.50 and $1.20 \mathrm{~s}$, respectively. Therefore, coagulation played an opposite role in relaxation time, i.e., it increased $\mathrm{T}_{1}$ while reduced $\mathrm{T}_{2}$ [15].

On the other hand, the relaxation curves of Figs. 1-3 showed trends similar to those observed using the same paramagnetic ion in aqueous solution (dotted lines). In aqueous solution, both relaxation times increased with $\mathrm{pH}$ at approximately, 3, 7, and 9, for $\mathrm{Fe}^{3+}$, $\mathrm{Cu}^{2+}$, and $\mathrm{Mn}^{2+}$, respectively [16].

The major differences in the relaxations between $\mathrm{CHI}$-ions and the respective ion in aqueous solution were observed with $\mathrm{Fe}^{3+}$ (Fig. 1a). The relaxation profiles of $\mathrm{CHI}-\mathrm{Fe}^{3+}$ solutions showed two turning points, at $\mathrm{pH} 2.9$ and 6.2. At $\mathrm{pH}$ values lower and higher than the first turning point, the relaxation times were 0.05 and $1.00 \mathrm{~s}$, respectively. However, $\mathrm{T}_{1}$ stayed at $1 \mathrm{~s}$ up to $\mathrm{pH} 4$ whereas $\mathrm{T}_{2}$ remained constant until $\mathrm{pH} 6 . \mathrm{T}_{1}$ increased again from $\mathrm{pH} 4$ to 7 and reached a plateau at $\mathrm{pH} 2.8 \mathrm{~s}$. $\mathrm{T}_{2}$ also increased from $\mathrm{pH} 6$ to 8 as well as reached a plateau at $1.5 \mathrm{~s}$.

When the CHI-Fe ${ }^{3+}$ solutions (Fig. 1a) were centrifuged, $\mathrm{T}_{1}($ profile showed a single turning point at $\mathrm{pH}$ 3.5. $\mathrm{T}_{1}$ values progressively increased from $0.11(\mathrm{pH} 2)$ to $2.8 \mathrm{~s}$ ( $\mathrm{pH} \mathrm{8-12).} \mathrm{On} \mathrm{the} \mathrm{other}$ hand, $\mathrm{T}_{2}(\mathrm{O})$ profile presented two turning points at $\mathrm{pH} 2.9$ and 6.9. $\mathrm{T}_{2}$ profile of the supernatant (Fig. 1b) was similar to that of the same sample prior to centrifugation (Fig. 1a). However, the first plateau at $1.2 \mathrm{~s}$, at $\mathrm{pH}$ values between 4 and 6.5 , was more defined in the $\mathrm{T}_{2}$ profile of the supernatant than in that of the solution. $\mathrm{T}_{2}$ profile
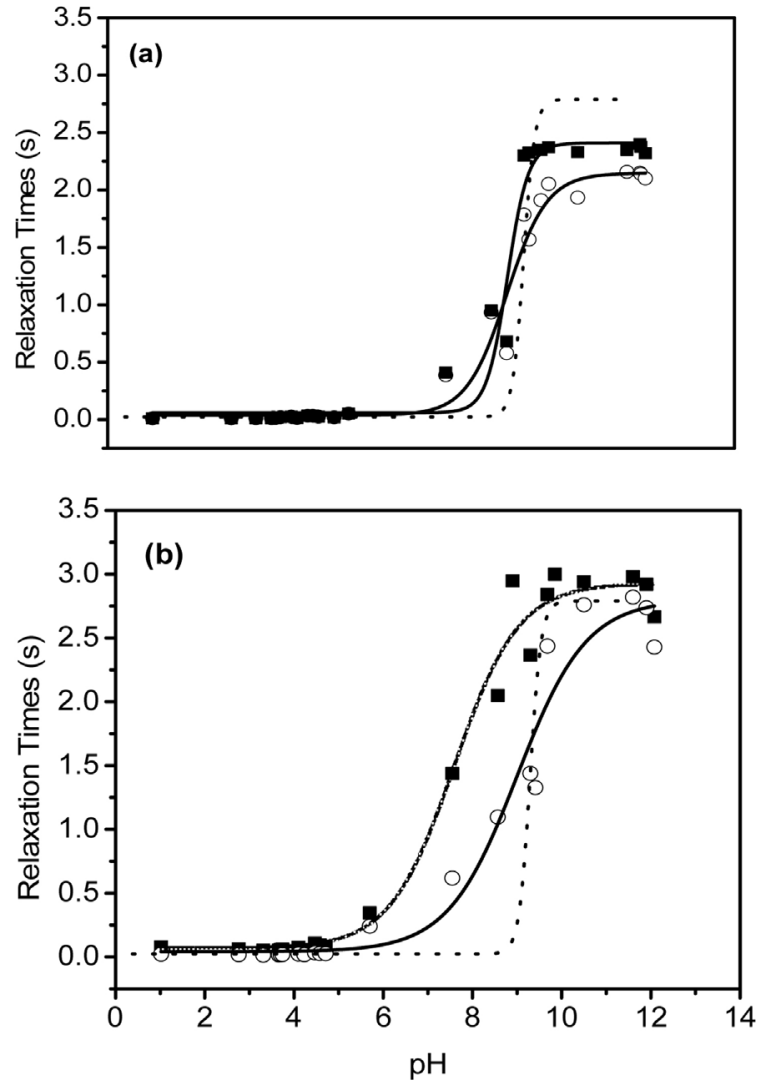

Fig. 3. $\mathrm{T}_{1}(\boldsymbol{\square})$ and $\mathrm{T}_{2}(\bigcirc)$ relaxometric profiles of $\mathrm{CHI}$-ion samples and supernatant obtained with $\mathrm{CP}-\mathrm{CWFP}_{\mathrm{x}-\mathrm{x}}$ pulse sequence. a) $\mathrm{CHI}-\mathrm{Mn}^{2+}$ and its respective supernatant. b) Solid and dotted lines are the sigmoidal fitting of experimental data acquired from $\mathrm{CHI}-\mathrm{Mn}^{2+}$ and $\mathrm{Mn}^{2+}$ aqueous solutions, respectively.

also showed a sharp increase between pH 6.7 (1.3 s) and $7.5(2.5 \mathrm{~s})$ and then stayed almost constant until $\mathrm{pH} 12$. The $\mathrm{T}_{2}$ value in this plateau was higher than those observed in CHI-ion (Fig. 1a) and aqueous ion solutions (dotted line).

Samples having $\mathrm{pH}$ within this range showed the same color changes and precipitations. At lower $\mathrm{pH}$ values, the solution was pale yellow and color intensity increased up to approximately $\mathrm{pH}$ 4.7. From $\mathrm{pH} 4.9$ to $\mathrm{pH} 7$, precipitation took place but the supernatant remained yellow. Above $\mathrm{pH} 7$, the supernatant became colorless.

The first turning point at ca. $\mathrm{pH} 3$ observed in the $\mathrm{T}_{1}$ profile of Fig. $1 \mathrm{a}$ and $\mathrm{T}_{2}$ profiles of Fig. $1 \mathrm{a}$ and $\mathrm{b}$ was remarkably close to that observed in $\mathrm{CHI}-$ free aqueous solution ( $\mathrm{pH} 3.2$, dotted line). This indicates that such turning was associated to the formation of insoluble iron hydroxides. However, no precipitation was observed in this pH range. Therefore, the relaxation profiles, color enhancement, and absence of precipitate indicate that some interaction occurred among $\mathrm{CHI}$ and $\mathrm{Fe}^{3+}$. The $\mathrm{CHI}-\mathrm{OH}$ groups must be involved in such interaction because amino groups are protonated at low $\mathrm{pH}$ values. This result agrees with other measurements performed elsewhere [1]. Therefore, the increase in relaxation times up to $\mathrm{pH}$ 4.9 can be related to the reduction of water accessibility to $\mathrm{Fe}^{3+}-$ which is partially protected by $\mathrm{CHI}$ - or to the formation of tiny $\mathrm{FeOOH}$ nanoparticles in the order of $5-10 \mathrm{~nm}$ - covered by a loose layer of adsorbed $\mathrm{CHI}$, as proposed by Sipos et al. [2].

The second turning points observed in $\mathrm{T}_{1}$ and $\mathrm{T}_{2}$ profiles of Fig. $1 \mathrm{a}$ and in $\mathrm{T}_{2}$ profile of Fig. $1 \mathrm{~b}$ were similar to that of the solution containing only $\mathrm{CHI}(\mathrm{pH} \cong 7)[15]$. These results suggest that such turning point occurred because of $\mathrm{CHI}$ coagulation/flocculation from the bulk. This hypothesis may be confirmed experimentally 
through the precipitation that occurred from $\mathrm{pH} 4.9$ to $\mathrm{pH}$ 7. Additionally, the low $T_{2}$ values $(\cong 1.50 \mathrm{~s})$ observed in Fig. 1a might be attributed to presence of free $\mathrm{Fe}^{3+}$ species in the bulk after complexation with $\mathrm{CHI}$, which is consistent with the yellow color observed in the supernatant within this $\mathrm{pH}$ range. Furthermore, the removal of $\mathrm{Fe}^{3+}$ species through $\mathrm{CHI}$ coagulation ( $\mathrm{pH} 7$ ) eliminated the yellow color of the supernatant and increased the relaxation times towards values close to the pure solvent $\left(\mathrm{T}_{1} \cong \mathrm{T}_{2} \cong 3.0 \mathrm{~s}\right.$ ) (Fig. $1 \mathrm{~b}$ ). Therefore, it is possible to one may infer that deprotonation of $\mathrm{CHI}-\mathrm{NH}_{2}$ groups occurred in this region. These groups are able to complex such ions as well as improve complexation efficiency, which justifies the increased relaxation times. These results are in accordance with the models proposed by Hernandéz et al. [1], who suggested the participation of deprotonated amino groups on $\mathrm{Fe}^{3+}$ complexation within this $\mathrm{pH}$ range, with additional water molecules or chloride ions completing the coordination sphere for such ion.

Conversely, the relaxation profiles of $\mathrm{CHI}$ aqueous solution in the presence of $\mathrm{Cu}^{2+}$ species (Fig. 2a) showed two plateaus from low to high $\mathrm{T}_{1}$ and $\mathrm{T}_{2}$ values with a transition at $\mathrm{pH} 6.2$, which was ca. 0.8 lower than the turning point observed for $\mathrm{Cu}^{2+}$ in aqueous solution (dotted line). For $\mathrm{CHI}-\mathrm{Cu}^{2+}$ and its respective supernatant (Fig. 2b), relaxation times were close to $0.46\left(\mathrm{~T}_{1}\right)$ and $0.3 \mathrm{~s}\left(\mathrm{~T}_{2}\right)$ up to $\mathrm{pH}$. Above the turning point of $\mathrm{CHI}-\mathrm{Cu}^{2+}$ (Fig. $2 \mathrm{a}$ ), $\mathrm{T}_{1}$ and $\mathrm{T}_{2}$ values reached a plateau at 1.00 and $0.50 \mathrm{~s}$, respectively. On the other hand, relaxation times for the supernatant were higher $\left(T_{1}=2.96\right.$ and $\mathrm{T}_{2}=2.60 \mathrm{~s}$ ), as observed in Fig. $2 \mathrm{~b}$. These were also similar to the relaxation times of pure water and of $\mathrm{CHI}$-free $\mathrm{Cu}^{2+}$ solution (dotted lines).

When the effects of $\mathrm{Fe}^{3+}$ (Fig. 1a) and $\mathrm{Cu}^{2+}$ (Fig. 2a) on CHI solutions are compared, it is observed that, after the turning point, the copper sample presented lower relaxation times than those of $\mathrm{Fe}^{3+}$ and $\mathrm{Cu}^{2+}$ aqueous solution (dotted line). Therefore, $\mathrm{Cu}^{2+}$ still affected water relaxation times in the presence of $\mathrm{CHI}$ at $\mathrm{pH}$ values higher than 7. This result suggests that a $\mathrm{CHI}-\mathrm{Cu}^{2+}$ complex was formed and that there were water molecules directly coordinated to metal ions. This hypothesis agrees with Modrzejewska [23] and Pestov and Bratskaya [3], who proposed that interactions among $\mathrm{CHI}-\mathrm{NH}_{2}$ groups and $\mathrm{Cu}^{2+}$ occur in two arrangements - known as pedant and bridge models - containing water molecules directly bonded to copper, which justifies the low relaxation times observed in Fig. 2a.

For the supernatant (Fig. 2b), the major difference occurred above the turning point, indicating that relaxation times were close to those of pure solvent as well as that such $\mathrm{CHI}-\mathrm{Cu}^{2+}$ complex was completely removed by an alkaline solution. This result is in agreement with experimental observations, wherein increased amounts of gelatinous blue precipitate as well as the presence of colorless supernatant were noticed. Similar results were reported by Cobra et al. [16]. According to these authors, metallic species precipitated as hydroxides at high $\mathrm{pH}$ values, reaching relaxation times close to those of pure solvents. Taking this observation into account, one may infer that, for a system containing the same ions but in the presence of $\mathrm{CHI}$, high hydroxyl contents can hydrolyze the complex and precipitate it, increasing $\mathrm{T}_{1}$ and $\mathrm{T}_{2}$ values.

The relaxation profiles of $\mathrm{CHI}-\mathrm{Mn}^{2+}$ sample (Fig. 3a) and its respective supernatant (Fig. $3 \mathrm{~b}$ ) exhibited low relaxation times $\left(0.06 \mathrm{~s}\right.$ for $\mathrm{T}_{1}$ and $0.02 \mathrm{~s}$ for $\left.\mathrm{T}_{2}\right)$ before the turning points. These values were similar to those observed in a $\mathrm{Mn}^{2+}$ aqueous solution [16]. These low values are attributed to the high relaxivity of $\mathrm{Mn}^{2+}$ when compared to $\mathrm{Cu}^{2+}$ and $\mathrm{Fe}^{3+}[16]$. The relaxation times in the presence of $\mathrm{CHI}$ showed a turning point at $\mathrm{pH}$ 8.90. This value was almost 0.4 lower than that of $\mathrm{Mn}^{2+}$ in water. Above the turning points of $\mathrm{CHI}-\mathrm{Mn}^{2+}$ solution, $\mathrm{T}_{1}$ was longer than $\mathrm{T}_{2}$, but smaller than the $T_{1}=T_{2}$ (dotted line) observed in aqueous solution. $T_{1}$ values of the supernatant (Fig. 3b) showed a lower turning point $(\mathrm{pH}$
7.6) than those of $\mathrm{T}_{2}(\mathrm{pH} 9.0)$ as well as $\mathrm{T}_{1}$ and $\mathrm{T}_{2}$ of $\mathrm{CHI}-\mathrm{Mn}^{2+}$ (Fig. 3a). Another difference between $\mathrm{CHI}-\mathrm{Mn}^{2+}$ and its respective supernatant is the $\mathrm{pH}$ at which $\mathrm{T}_{1}$ begins to increase. In the supernatant, the variation started at $\mathrm{pH}$ values lower than 6 (Fig. 3b), whereas in the $\mathrm{CHI}-\mathrm{Mn}^{2+}$ sample (Fig. 3a) it started at $\mathrm{pH} 7$.

$\mathrm{CHI}-\mathrm{Mn}^{2+}$ had a minor effect on water relaxation times when compared to the values measured in an aqueous solution of the same ions. Most of the observed differences could be explained by $\mathrm{CHI}$ coagulation at $\mathrm{pH}$ higher than 6 . This process removes $\mathrm{Mn}^{2+}$ by flocculation, which justifies the similarity between the obtained relaxometric profiles. These results indicate that the $\mathrm{CHI}-$ $\mathrm{Mn}^{2+}$ complex had a low stability constant and that these species are mostly removed by the action of $\mathrm{pH}$. This hypothesis is in line with results reported elsewhere $[24,25]$ and may be corroborated experimentally through the emergence of a gelatinous, dark brown precipitate upon increased alkalinity. This is attributed to $\mathrm{Mn}(\mathrm{OH})_{2}$ and $\mathrm{CHI}$ flocculation.

Finally, the high relaxation times ( $\cong 2.70 \mathrm{~s}$ ) of supernatant samples (Figs. 1b, 2b, and 3b) demonstrated the high efficiency of $\mathrm{CHI}$ in cleaning the solution by removing $\mathrm{Fe}^{3+}, \mathrm{Cu}^{2+}$, and $\mathrm{Mn}^{2+}$ ions. This observation agrees well with data previously reported in the literature [1,23-25]. It also corroborates the ability of TD-NMR relaxometry in monitoring chitosan-paramagnetic ion interactions in solution.

\section{Conclusions}

Based on the results presented here, one may conclude that simultaneous measurements of $\mathrm{T}_{1}$ and $\mathrm{T}_{2}$ relaxation times by $\mathrm{CP}-$ $\mathrm{CWFP}_{\mathrm{x}-\mathrm{x}}$ pulse sequence in a benchtop TD-NMR relaxometer stands out as a fast, efficient method to study $\mathrm{CHI}$-paramagnetic ion interactions in aqueous solution. The relaxation profiles of $\mathrm{CHI}-\mathrm{Fe}^{3+}$ aqueous solutions demonstrated that $\mathrm{CHI}$ interaction with these ions are affected by $\mathrm{pH}$. At $\mathrm{pH}$ values lower than 5 , CHI interacted with $\mathrm{Fe}^{3+}$ ions or iron oxide nanoparticles and maintained the metal ion in solution. At $\mathrm{pH}$ values higher than $7, \mathrm{CHI}$ coagulated and removed Fe ions or nanoparticles, resulting in a clear supernatant. On the other hand, $\mathrm{CHI}-\mathrm{Cu}^{2+}$ relaxation profiles indicated the direct formation of a stable complex with water molecules directly linked to the paramagnetic ion. As for $\mathrm{CHI}-\mathrm{Mn}^{2+}$, the results suggested the formation of an unstable complex in solution, which was removed though coagulation at alkaline $\mathrm{pH}$. Although the measurements were performed with $\mathrm{Fe}^{3+}, \mathrm{Cu}^{2+}$, and $\mathrm{Mn}^{2+}$ here, these can also be used to study $\mathrm{CHI}$ interactions with other paramagnetic ions, including $\mathrm{Cr}^{3+}, \mathrm{Ni}^{2+}, \mathrm{Co}^{2+}, \mathrm{Mo}^{2+}$, and $\mathrm{V}^{3+}$ ions that are dangerous pollutants. Furthermore, TD-NMR relaxometry can be used to study interactions among paramagnetic ions and others $\mathrm{CHI}$ molecules of different molecular weights, acetylation degrees, and derivatives as well as between other water-soluble polysaccharides and paramagnetic ions.

\section{Acknowledgements}

The authors would like to thank the Brazilian agencies FAPESP (grants 2012/23169-8 and 2014/22126-9) and CNPq (grants 303837/2013-6 and 403075/2013-0), for their financial support.

\section{References}

[1] R.B. Hernandez, A.P. Franc, O.R. Yola, A. Lopez-Delgado, J. Felcman, M.A.L. Recio, A.L.R. Merce, Coordination study of chitosan and $\mathrm{Fe}^{3+}$, J. Mol. Struct. 877 (2008) 89-99.

[2] P. Sipos, O. Berkesi, E. Tombácz, T.G. Pierre, J. Webb, Formation of spherical iron (III) oxyhydroxide nanoparticles sterically stabilized by chitosan in aqueous solutions, J. Inorg. Biochem. 95 (2003) 55-63.

[3] A. Pestov, S. Bratskaya, Chitosan and Its derivatives as highly efficient polymer ligands, Molecules 21 (2016) 330-365. 
[4] A.S. Portnyagin, S. Bratskaya, A.V. Pestov, A.V. Voit, Binding Ni(II) ions to chitosan and its $\mathrm{N}$-heterocyclic derivatives: density functional theory investigation, Comput. Theor. Chem. 1069 (2015) 4-10.

[5] I.M.N. Vold, K.M. Varum, E. Guibal, O. Smidsrod, Binding of ions to chitosan-selective studies, Carbohyd. Polym. 54 (2003) 471-477.

[6] W.S. Wan Ngah, L.C. Teong, M.A.K.M. Hanafiah, Adsorption of dyes and heavy metals by chitosan composites: a review, Carbohyd. Polym. 83 (2011) $1446-1456$.

[7] F. Renault, B. Sancey, P.M. Badot, G. Crini, Chitosan for coagulation/flocculation processes-an eco-friendly approach, Eur. Polym. J. 45 (2009) 1337-1348.

[8] A.J. Varma, S.V. Deshpande, J.F. Kennedy, Metal complexation by chitosan and its derivatives: a review, Carbohyd. Polym. 55 (2004) 77-93.

[9] R.Q. Lu, Z.G. Cao, G.P. Shen, Comparative study on interaction between copper (II) and chitin/chitosan by density functional calculation, J. Mol. Struc. Theochem. 860 (2008) 80-85.

[10] E. Guibal, T. Vincent, R. Navarro, Metal ion biosorption on chitosan for the synthesis of advanced materials, J. Mater. Sci. 49 (2014) 5505-5518

[11] F. Brunel, N.E. El Gueddari, B.M. Moerschbacher, Complexation of copper(II) with chitosan nanogels: toward control of microbial growth, Carbohyd. Polym. 92 (2013) 1348-1356.

[12] Y.A. Azarova, A.V. Pestov, Y.A. Ustinov, S.Y. Bratskaya, Application of chitosan and its $\mathrm{N}$-heterocyclic derivatives for preconcentration of noble metal ions and their determination using atomic absorption spectrometry, Carbohyd. Polym. 134 (2015) 680-686.

[13] F.G.L.M. Borsagli, A.A.P. Mansur, P. Chagas, L.C.A. Oliveira, H.S. Mansur, O-Carboxymethyl functionalization of chitosan: complexation and adsorption of Cd (II) and Cr (VI) as heavy metal pollutant ions, React. Funct. Polym. 97 (2015) 37-47.

[14] A. Webster, M.D. Halling, D.M. Grant, Metal complexation of chitosan and its glutaraldehyde cross-linked derivative, Carbohyd. Res 342 (2007) 1189-1201.

[15] F.V.C. Kock, L.A. Colnago, Rapid method for monitoring chitosan coagulation using low-field NMR relaxometry, Carbohyd. Polym. 150 (2016) 1-4
[16] P.F. Cobra, B.F. Gomes, C.I.N. Mitre, L.L. Barbosa, L.V. Marconcini, L.A. Colnago, Measuring the solubility product constant of paramagnetic cations using time-domain nuclear magnetic resonance relaxometry, Microchem. J 121 (2015) 14-17

[17] F.V.C. Kock, L.A. Colnago, Rapid and simultaneous relaxometric methods to study paramagnetic ion complexes in solution: an alternative to spectrophotometry, Microchem. J. 122 (2015) 144-148.

[18] T.B. Moraes, T. Monaretto, L.A. Colnago, Rapid and simple determination of $\mathrm{T}_{1}$ relaxation times in time-domain NMR by continuous wave free precession sequence, J. Magn. Reson. 270 (2016) 1-6.

[19] T. Monaretto, F.D. Andrade, T.B. Moraes, A.A. Souza, E.R. de Azevedo, L.A Colnago, On resonance phase alternated CWFP sequences for rapid and simultaneous measurement of relaxation times, J. Magn. Reson. 259 (2015) 174-178.

[20] W.G. Birolli, J.A.M. Delezuk, S.P. Campana-Filho, Ultrasound-assisted conversion of alpha-chitin into chitosan, Appl. Acoust. 103 (2016) 239-242.

[21] M.R. Kasaai, Calculation of Mark-Houwink-Sakurada (MHS) equation viscometric constants for chitosan in any solvent-temperature system using experimental reported viscometric constants data, Carbohyd. Polym. 68 (2007) 477-488.

[22] M.R. Kasaai, Determination of the degree of $\mathrm{N}$-acetylation for chitin and chitosan by various NMR spectroscopy techniques: a review, Carbohyd. Polym. 79 (2010) 801-810.

[23] Z. Modrzejewska, Sorption mechanism of copper in chitosan hydrogel, React. Funct. Polym. 73 (2013) 719-729.

[24] Z.B. Wu, W.N. Ni, B.H. Guan, Application of chitosan as floculant for coprecipitation of $\mathrm{Mn}(\mathrm{II})$ and suspended solids from dual-alkali FGD regenerating process, J. Hazard. Mater. 152 (2008) 757-764.

[25] S.C. Bhatia, N. Ravi, A magnetic study of a Fe-chitosan complex and its relevance to other biomolecules, Biomacromolecules 1 (2000) 413-417. 